\section{Le médecin du prince. Voyage à travers les cultures}

Anne Marie Moulin. Odile Jacob, Paris, 2010, 368 p, $25 €$

ANNE MARIE MOULIN

\section{LE MÉDECIN DU PRINCE}

VOYAGE À TRAVERS LES CULTURES
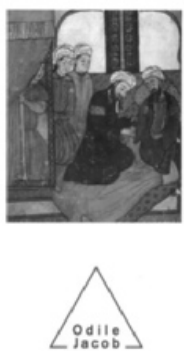

Pourquoi les princes ont-ils depuis toujours choisi d'être soignés par des médecins étrangers ?

Ainsi Maïmonide, médecin du sultan Saladin sous les croisades, Vésale, médecin de Charles Quint, Bernier, attaché au Grand Moghol à l'époque de LouisXIV, le Grenoblois Clot-Bey qui fonda l'école de médecine du Caire en 1827, ou encore cette femme qui radiographia pour la première fois le roi du Yémen dans les années 1950 et cette doctoresse britannique que le souverain d'Afghanistan s'attacha au tournant $\mathrm{du} \mathrm{XIX}^{\mathrm{e}}$ au $\mathrm{Xx}^{\mathrm{e}}$ siècle.

Anne Marie Moulin montre comment le médecin du prince a joué de multiples rôles, à l'intersection du pouvoir et du savoir. Comment il a contribué à l'organisation de la profession médicale et à la régulation de ses pratiques. Comment il a pris part aux innovations thérapeutiques et encouragé la recherche. Comment, face aux épidémies, il a consolidé la domination du prince et préfiguré les politiques de santé publique en faveur du peuple.

Un récit qui témoigne de l'universalité de la médecine dans l'entrechoc des cultures et des civilisations.

Anne Marie Moulin, normalienne, interne des hôpitaux, est médecin et directrice de recherches en philosophie au CNRS. 